\title{
A IMPORTÂNCIA DOS ITENS FUNCIONAIS NA ETAPA INICIAL DE AQUISIÇÃO DA LINGUAGEM
}

Danielle Novais Uchôa é mestra em Linguística pela UFJF

E-mail: uchoa.danielle@gmail.com

Sabrina Anacleto Teixeira é mestra em Linguística pela UFJF

E-mail: sabrinaanacleto30@gmail.com

\section{Resumo}

Este trabalho trata da importância dos itens funcionais nas etapas iniciais de aquisição da linguagem, mostrando de que forma a criança reconhece esses itens e os utiliza para inserção na gramática da língua. Para isso, consideramos um modelo de língua - Programa Minimalista e um modelo psicolinguístico - bootstrapping fonológico-e, ainda, apresentamos trabalhos em diversas línguas que oferecem evidências de que, desde muito cedo, as crianças são sensíveis aos itens funcionais, usando-os como pistas para aquisição de sua língua.

\begin{abstract}
This work deals with the importance of function words in the early steps of language acquisition, showing how the child recognize these items and use them to enter her language's grammar. For this, we consider a language model- Minimalist Program and a psycholinguistic model - phonological booststrapping - and, also, we present several works in different languages that provide evidences that, since very early, children are sensible to function items, using them as cues to acquire their language.
\end{abstract}

\section{1) Introdução:}

Os elementos das categorias funcionais são fundamentais no processo de aquisição de uma língua, visto que podem ser considerados "âncoras" para predizer relações entre categorias em uma análise distribucional e, assim, seriam essenciais para a aquisição das categorias lexicais e construção das relações sintáticas da língua. Do ponto de vista perceptual, os itens funcionais se distinguem dos itens lexicais por suas propriedades fonéticas, prosódicas e distribucionais; por exemplo, apresentam um número mínimo de sílabas, são preferencialmente átonos e, geralmente, se realizam por meio de fones fracos. Além disso, são altamente frequentes e têm distribuição característica, tornando-se previsíveis no contexto sintático. Diferentemente, os itens lexicais não obedecem a um padrão fônico característico, existem em grande número, com frequência variada, não sendo, portanto, previsíveis em função do contexto sintático. Essas características estão presentes no input ao qual a criança tem acesso. Dessa forma, a partir do momento em que o bebê é sensível a essas características, poderia começar a agrupar os itens de sua língua separadamente, levando a uma distinção preliminar entre categorias lexicais e funcionais. Assumimos, portanto, que a sensibilidade a elementos de categorias funcionais tem papel fundamental no desencadeamento do processo de aquisição de uma língua (Corrêa, 2012).

No entanto, a delimitação dessas unidades depende da percepção e da análise do sinal acústico da fala, resultando na segmentação do mesmo em unidades sintáticas e lexicais. Cabe à criança, exposta aos dados linguísticos apresentados na fala natural do adulto, que ocorre de forma contínua, sem pausas entre as palavras, segmentar o fluxo da fala em unidades relevantes ao processamento linguístico, ainda que não tenha domínio do sistema fonológico e do léxico da língua com a qual está em contato. De acordo com Morgan \& Demuth (1996) e Christophe e colaboradores (1997), o bootstrapping fonológico é a hipótese de que uma análise fonológica do sinal da fala 
pode permitir às crianças adquirirem o léxico e a sintaxe de sua língua. Esta proposta surge como questão relevante para o processo de aquisição da linguagem, visto que a tarefa inicial da criança deve ser a segmentação do fluxo da fala em unidades menores que ajudem no processamento linguístico, pressupondo que a criança, desde os primeiros dias de vida, esteja atenta a pistas recorrentes da língua. Assim, diante de um continuum sonoro linguístico, em um primeiro momento, há a segmentação do fluxo da fala em unidades cada vez menores e, posteriormente, a distinção entre elementos lexicais e funcionais a partir da identificação e generalização de padrões distribucionais, fonotáticos e prosódicos - viabilizando a aquisição da estrutura sintática e, consequentemente, do léxico de sua língua materna. Entretanto, ainda que a criança identifique no continuum sonoro as propriedades fonéticas / fonológicas, os padrões recorrentes da língua e, mais especificamente, os traços formais dos elementos funcionais da língua, é preciso assumir uma predisposição inata para a aquisição lexical e sintática de sua língua (Corrêa, 2012). Dessa forma, torna-se interessante a integração do modelo de processamento assumido neste trabalho - Bootstrapping fonológico com um modelo de língua - Programa Minimalista (CHOMSKY 1995 e desenvolvimentos posteriores) - a fim de tentar explicar o problema lógico da aquisição de uma língua: como ocorre a representação formal da língua a partir dos dados prosódicos/ fonológicos extraídos do continuum sonoro. Tal integração se torna possível, na medida em que o modelo linguístico prevê uma interface da língua com os sistemas intencional-conceptual e sensório-motor, e a abordagem psicolinguística considera a análise fonológica do continuum da fala como uma forma de viabilizar ou potencializar a aquisição da linguagem. Por meio dessa perspectiva, buscamos explicar como as crianças, sensíveis às pistas distribucionais e fonotáticas, segmentam o sinal acústico da fala em unidades menores, levando assim à estrutura sintática subjacente à língua. Análises estatísticas e mecanismos de abstração e generalização também são recursos precocemente disponíveis e explorados por bebês no processo de categorização de elementos lexicais (MARCUS et al., 1999; GOMEZ, 2002; NEWPORT \& ASLIN, 2004).

Portanto, os objetivos específicos deste artigo são apresentar uma abordagem conciliatória de um modelo formal de língua e um modelo psicolinguístico voltado à aquisição, com vistas a explicar de que forma a criança adquire a gramática de sua língua. Além disso, apresentamos resultados experimentais em diversas línguas que apresentam evidências do papel facilitatório dos itens funcionais na aquisição da linguagem, em especial, trabalhos realizados em Português do Brasil.

O artigo está organizado da seguinte forma: a seção seguinte é dedicada aos pressupostos teóricos que norteiam este trabalho: o Programa Minimalista (PM) e a hipótese do bootstrapping fonológico. Já na terceira seção, apresentamos um panorama de diversos trabalhos acerca dos itens funcionais como elementos desencadeadores do processo de aquisição da linguagem. Por fim, na última seção, são apresentadas as considerações finais. 


\section{2) Pressupostos teóricos}

\section{1) A hipótese do bootstrapping fonológico}

Os estudos psicolinguísticos voltados à aquisição da linguagem buscam compreender como se dá o processo pelo qual os bebês identificam a gramática de sua língua. Neste processo, a tarefa do bebê é segmentar o fluxo da fala em unidades que, combinadas, constituem enunciados, de modo a reconhecer padrões e tecer generalizações acerca das propriedades da língua.

O Bootstrapping fonológico (Morgan \& Demuth, 1996; Christophe et al, 1997) fundamenta-se no pressuposto de que os enunciados da língua são perceptualmente acessíveis às crianças desde muito cedo. Dessa forma, informações extraídas do continuum da fala serviriam de pistas capazes de alavancar a estrutura sintática da língua, desencadeando o processo de aquisição do léxico e da sintaxe de sua língua.

Nessa proposta, o mapeamento entre som e sentido ocorreria em dois momentos distintos. Primeiramente, uma análise do fluxo da fala desencadearia a aquisição lexical e, em um segundo momento, ocorreria o pareamento entre as formas de palavras e seu sentido.

Assim, a partir de seu aparelho perceptual e diante dos estímulos aos quais está exposta, a criança é capaz de reconhecer informações distribucionais, fonotáticas e prosódicas que viabilizam a identificação dos itens do léxico e da estrutura sintática de sua língua.

\section{2) O Programa Minimalista (PM)}

O modelo do bootstrapping fonológico buscou explicar de que modo o processo de aquisição da linguagem é desencadeado. No entanto, essa proposta torna-se insuficiente para demonstrar de que forma essas informações acessadas no plano fonético / fonológico são transpostas para o plano de realização formal e, ainda, o que de fato a criança deve adquirir. Dessa forma, faz-se necessário conciliar um modelo de processamento com uma teoria de língua - Programa Minimalista.

O Programa Minimalista está inserido na linguística gerativa chomskyana, mas, se por um lado, dá seguimento à Teoria dos Princípios e Parâmetros, postulada nos anos 80, por outro apresenta uma inovação ao explicitar as restrições à forma das gramáticas como decorrente da interface da língua com os demais sistemas cognitivos necessários à aquisição linguística (cf. Corrêa, 2008, p, 181).

Nessa perspectiva, entende-se a faculdade da linguagem sob duas perspectivas: no sentido estrito (FLN - Faculty of Language in the narrow sense) e no sentido amplo (FLB - Faculty of Language in the broad sense). A FLN incorpora um sistema computacional, responsável pela computação sintática. Este sistema caracteriza-se por ser estritamente linguístico, universal e por atuar de forma independente dos outros 
sistemas com os quais interage, gerando representações internas que são projetadas nas outras interfaces.

No Minimalismo, concebe-se a língua como um componente interno da mente/cérebro (Língua-I) formado pela FLN e um léxico. Este léxico é composto por elementos pertencentes a categorias lexicais e funcionais. Ao contrário do caráter inato do sistema computacional, o léxico é adquirido a partir da experiência, sendo, pois, responsável pelas especificidades de cada língua. O léxico é caracterizado, portanto, como um componente da Língua-I, formado por traços. É nesse componente que são instanciadas as variações (parâmetros) entre as línguas, já que as particularidades de cada sistema linguístico residem nos traços formais que são ou não tomados como relevantes naquela língua.

Os elementos que constituem o léxico são compostos por traços semânticos, fonológicos e formais, sendo que o sistema computacional atua somente sobre os traços formais (traços categoriais, tais como $\mathrm{N}(\mathrm{ome}) \mathrm{V}$ (erbo), etc.; traços phi (gênero, número e pessoa) e traços de Caso). Sendo assim, somente esses traços são acessíveis ao sistema computacional e podem ser passados à Forma Lógica (LF) para serem interpretados.

Já a FLB compreende a FLN e os sistemas cognitivos de desempenho com os quais faz interface. Nesse sentido, na perspectiva minimalista, o sistema computacional corresponderia ao que é inato, específico da espécie humana, constituindo-se, portanto, do estado inicial de aquisição de uma língua.

No entanto, como vimos, a aquisição e também o processamento da linguagem pressupõe a interface do sistema computacional com os demais sistemas cognitivos relacionados à linguagem. Os sistemas com os quais a FLN faz interface são o sistema sensório-motor (articulatório-perceptual) e o sistema conceitual-intencional (pensamento).

Nessa perspectiva, uma língua $L$ fornece informações a esses sistemas de interface através de níveis de representação linguística. $\mathrm{O}$ nível que faz interface com o sistema articulatório-perceptual é a Forma Fonética (PF), ou seja, a interface fonética. Já a Forma Lógica (LF), que corresponde à interface semântica, dialoga com o sistema conceptual-intencional.

Diante dessa visão, o processo de aquisição da linguagem pressupõe a constituição, a partir de um sistema computacional, de um léxico mínimo, bem como a identificação dos traços formais que constituem a língua.

Os itens funcionais tornam-se relevantes nesse processo, já que são caracterizados por apresentarem traços formais, responsáveis pelas informações gramaticais da língua. Assim, a partir do reconhecimento dos traços formais destes itens, a criança tem acesso à gramática de sua língua e o processo de aquisição é desencadeado. Dessa forma, o Programa Minimalista confere um status especial aos itens funcionais, na medida em que os parâmetros de variação entre as línguas residem nas propriedades dos traços formais desses elementos.

De acordo com a proposta de integração entre esses dois modelos, informações disponíveis desde muito cedo à criança no continuum da fala desencadeariam o funcionamento do sistema computacional, dando início ao processo de aquisição. 
Na medida em que o sistema computacional configura-se como um componente inato à espera de ser acionado, a percepção de padrões fonológicos e prosódicos disponíveis no fluxo da fala e reconhecidos pela criança, possibilitaria-lhes a diferenciação entre itens lexicais e funcionais, o que permitiria a construção de um léxico mínimo, constituído por um número mínimo de traços formais e, por conseguinte, a inicialização do sistema computacional. Essa inicialização permitiria que uma análise sintática (parsing) fosse conduzida, permitindo que categorias funcionais e lexicais sejam gradativamente diferenciadas. Por fim, o pressuposto de que enunciados linguísticos referem-se a entidades e eventos dá início ao processamento na interface semântica. Somente após este momento em que ocorre a interpretação semântica das expressões linguísticas geradas, o processo de aquisição seria concluído.

Diante dessa conciliação, assume-se que os itens funcionais estariam disponíveis na interface fônica e seriam salientes para as crianças, dadas as suas propriedades fonéticas, prosódicas e distribucionais. A partir de seu aparato perceptual, a criança reconheceria esses itens, promovendo a distinção das categorias funcionais e lexicais, o que torna possível a criação de um léxico mínimo e subespecificado, desencadeando a inicialização do sistema computacional e o processo de aquisição de sua língua.

\section{3) Sensibilidade de bebês aos itens funcionais}

Uma série de trabalhos em diferentes línguas vem se debruçando sobre o papel dos itens funcionais nas etapas iniciais do processo de aquisição da linguagem, sugerindo que os bebês, desde muito cedo já são sensíveis a esses itens.

Em um conjunto de experimentos, Shady (1996) investigou a sensibilidade de crianças de 10.5 meses aos itens funcionais e sua contribuição para a identificação e categorização de palavras no fluxo da fala, através da técnica de escuta preferencial ${ }^{1}$. O primeiro experimento teve por objetivo atestar a sensibilidade aos itens funcionais. Foram criadas duas condições experimentais, consistindo de uma versão modificada da história e de outra não-modificada. A condição não-modificada consistia de seis passagens curtas de texto, que apresentavam os seguintes itens funcionais: was, is, the, $a$, of, with, that. Já para a versão modificada, foram criados itens funcionais que não obedeciam às propriedades prosódicas e segmentais dessa categoria, tais como a presença de uma vogal reduzida sozinha e uma consoante fricativa. A média de tempo de escuta para a condição não modificada $(7.86 \mathrm{sec})$ foi significativamente maior $(\mathrm{p}<$. $005)$ do que para a condição modificada $(6.34 \mathrm{sec})$.

Em um segundo experimento, os pseudoitens foram substituídos por itens semelhantes fonotaticamente aos itens do inglês, de forma a verificar se as crianças seriam sensíveis às propriedades fônicas desses elementos. De acordo com a previsão, se as crianças já são sensíveis à forma fônica dos itens funcionais nessa idade, o tempo de escuta para a condição não modificada será maior, de acordo com o resultado do

\footnotetext{
${ }^{1}$ Para maior detalhamento acerca dessa e de outras técnicas experimentais, consultar NAME, M. C. ; Corrêa, L.M.S.(2006).
} 
experimento anterior, ainda que fonicamente os dois conjuntos de itens sejam semelhantes.

A análise dos resultados demonstrou uma preferência para a condição nãomodificada $(9.04 \mathrm{sec})$ em relação à outra $(7.12 \mathrm{sec})$, conforme previsto. Ou seja, os dados sugerem que aos 10.5 meses, as crianças já apresentariam um conhecimento acerca dos padrões fonológicos dos itens funcionais, preferindo os itens funcionais verdadeiros em detrimento dos pseudoitens criados.

O terceiro experimento visou a testar se as crianças estavam simplesmente reagindo a itens desconhecidos ou às propriedades acústico-fonológicas dos itens funcionais. Dessa vez, os itens lexicais foram trocados por pseudoitens, ao passo que os itens funcionais foram preservados. O tempo de escuta para a condição não modificada foi de $7.82 \mathrm{sec}$ e para a modificada $7.84 \mathrm{sec}$. A diferença do tempo de escuta para as duas condições não foi significativa $(\mathrm{p}=.98)$. O fato de as crianças não estranharem os pseudoitens lexicais sugere que não estão apenas distinguindo sons familiares ou não, mas sim, reconhecendo as propriedades fonológicas dos itens funcionais.

A fim de verificar se crianças nessa idade também são sensíveis às propriedades distribucionais desses elementos, sendo capazes de distinguir o conjunto de itens que são combinados com nomes daqueles que aparecem com verbos, um quarto experimento foi realizado. Na condição modificada, os itens funcionais que precedem nomes (the, of, a, with, that) foram combinados com verbos, e aqueles que ocorrem diante de verbos (was, is, has, have, had) aparecem antecedidos de nomes. A hipótese é de que, nesta idade, as crianças são sensíveis aos padrões de coocorrência dos itens funcionais. A previsão, portanto, é de que o tempo de escuta seria maior para a condição não-modificada. De acordo com os resultados, aos 10.5 meses de idade, os bebês não são sensíveis ao padrão distribucional desses itens $(\mathrm{p}=.16)$.

Uma vez que crianças de 10.5 meses de idade ainda não identificariam a propriedade distribucional dos itens funcionais, o mesmo experimento foi realizado com bebês mais velhos, de 12.5 e 16 meses. A diferença no tempo médio de escuta entre as condições para os bebês de 12.5 meses também não se mostrou significativa $(p=.514)$. Já para as crianças de 16 meses a diferença mostrou-se marginalmente significativa estatisticamente $(\mathrm{p}=.056)$, sugerindo que é por volta desta idade que a criança apresenta certa sensibilidade aos padrões distribucionais dos itens funcionais, preferindo ouvir por mais tempo a condição não - modificada $(8.07 \mathrm{sec})$ à modificada $(6.31 \mathrm{sec})$.

A análise dos resultados encontrados por Shady (1996) sugere que as crianças já se mostram sensíveis às propriedades fônicas dos itens funcionais aos 10.5 meses de idade, mas somente em um momento posterior, por volta dos 16 meses, reconheceriam as suas características distribucionais, sendo capazes de delimitar e reconhecer quais itens antecedem os nomes e quais são utilizados com verbos.

Utilizando a técnica de Potenciais Evocados (ERPs), Shafer e colaboradores (1998) investigaram a amplitude e latência dos potenciais evocados em bebês entre $10 \mathrm{e}$ 11 meses adquirindo o inglês em termos cerebrais. Os vinte bebês escutaram histórias na condição normal, em que foram utilizados itens funcionais do inglês, e na condição modificada, em que houve a substituição por pseudo-itens. 
Em relação aos bebês de 11 meses, os potenciais evocados na condição modificada apresentaram baixa amplitude, o que significa maior utilização de recursos neurais, em relação à outra condição. A diferença significativa $(\mathrm{p}<0.05)$ entre as duas condições sugeriu, portanto, que aos 11 meses as crianças são sensíveis aos itens funcionais. Já os bebês de 10 meses não apresentaram diferença significativa, sugerindo que o reconhecimento, em termos cerebrais, desses itens se daria por volta dos 11 meses de idade.

Ainda em relação à sensibilidade aos itens funcionais, Hohle e Weissenborn (2003) conduziram experimentos com crianças alemãs de 7.5 meses de idade. Os estímulos eram formados por quatro pseudoitens funcionais, dos quais dois eram preposições - bis (to) e von (from) - e dois determinantes: das (the) e sein (his). Para cada item, foi criada uma passagem de texto constituída de seis sentenças, de forma que o item em questão aparecesse uma única vez em cada uma das sentenças.

$\mathrm{Na}$ fase de familiarização, foram apresentados os pseudoitens isoladamente e na fase teste, as crianças ouviam às passagens de texto. Durante a familiarização, cada criança ouvia dois elementos, um determinante e uma preposição, apresentados isoladamente. Após escutarem por $30 \mathrm{sec}$ cada item apresentado, procediam à fase seguinte. Já durante o teste, todas as crianças ouviam frases curtas contendo os quatro itens funcionais.

Através da técnica de escuta preferencial mediu-se o tempo de escuta em relação às passagens que continham os itens familiarizados e aquelas que não apresentavam os itens familiarizados. A diferença mostrou-se significativa estatisticamente $(\mathrm{p}=.011)$, sugerindo que já aos 7.5 meses, crianças alemãs já detectam os itens funcionais de sua língua.

O mesmo experimento foi conduzido com o objetivo de investigar a sensibilidade de crianças mais novas, com 6 meses de idade, porém, a diferença no tempo de escuta não se mostrou significativa.

A série de trabalhos mencionados trata da sensibilidade aos itens funcionais na etapa inicial da aquisição da linguagem. A seguir, são apresentados trabalhos que investigam especificamente a sensibilidade aos determinantes, que são subconjunto da categoria de elementos funcionais.

Shi e colaboradores (2003) investigaram a sensibilidade de bebês aos determinantes com crianças de 8 meses de idade, adquirindo o inglês.

$\mathrm{Na}$ condução da atividade experimental, foram utilizados cinco determinantes do inglês: the, his, her, their and its, e cinco itens inventados que seguiam o padrão fonotático da língua: kuh, ris, ler, lier e ots. Além disso, foram criados dois pseudonomes: tink e doomp.

Duas condições experimentais foram criadas: pseudonome antecedido de determinante "real" e pseudonome antecedido de pseudodeterminante. Na familiarização de um grupo de bebês, um item real era combinado a tink e um pseudodeterminante antecedia doomp. Para o outro grupo de bebês, na familiarização, havia frases contendo um pseudoitem seguido de tink e itens reais combinados a doomp. Os ensaios dessas condições foram apresentados assim, de modo a variar a combinação entre os Dets e os Ns. No teste, para cada uma das condições, três ensaios contendo 
determinantes eram alternados com outros três contendo pseudoitens seguidos de ambos os pseudonomes.

Os sujeitos da pesquisa foram 16 crianças de oito meses de idade, divididas em dois grupos. A técnica utilizada foi a fixação do olhar, em que estímulos sonoros eram apresentados concomitantemente a uma imagem, enquanto o tempo em que a criança fixa o olhar na tela é medido.

A hipótese assumida é de que nesta idade, as propriedades fônicas dos determinantes já seriam reconhecidas pelas crianças, o que seria sugerido por um tempo de escuta maior para a condição normal em relação à modificada.

A média de escuta para a condição modificada foi de $38.48 \mathrm{sec}$ e para a não modificada de $37.88 \mathrm{sec}$. Tal diferença não se mostrou significativa, sugerindo que crianças de 8 meses de idade não são sensíveis a esses elementos.

Uma possível explicação para esse resultado pode ter sido, segundo as autoras, pela inadequação da palavra doomp, uma vez que não é comum a interveniência de vogais duplicadas antes de $m p$.Dessa forma, na realização de um segundo experimento, substituiu-se tal palavra por breek, que corresponde mais satisfatoriamente aos padrões fonotáticos da língua inglesa. Assim como no primeiro, não houve diferença significativa no tempo de olhar para as duas condições.

$\mathrm{Na}$ tentativa de se determinar se crianças mais velhas reconheceriam esses itens, um terceiro experimento foi conduzido com bebês de 13 meses.

De acordo com o esperado, os bebês demonstraram sensibilidade aos determinantes da língua $(\mathrm{p}=.006)$, fixando o olhar por mais tempo quando ouviam determinantes reais $(36.46 \mathrm{sec})$ em relação aos pseudodeterminantes $(32.84 \mathrm{sec})$. Como os determinantes criados diferiam minimamente em relação aos reais, tais resultados sugerem que aos 13 meses, as crianças não apenas reconhecem os determinantes de sua língua, mas também os representam com propriedades segmentais específicas.

A partir dos resultados obtidos nos trabalhos apresentados fica evidenciado que o reconhecimento dos determinantes ocorre entre os 8 e 13 meses de idade.

Cabe ressaltar que os experimentos realizados por Shi e colaboradores (2003) e Shady (1996), realizados com bebês de 8 e 10.5 meses, respectivamente, divergem de Shafer e colaboradores (1998), que sugeriram que a sensibilidade aos itens funcionais ocorreria somente aos 11 meses de idade.

Uma possível explicação para essa diferença de resultados pode estar nos estímulos usados. A utilização de unidades menores (sintagmas) no experimento de Shi e colaboradores pode ter facilitado a percepção dos determinantes pelas crianças mais novas.

Em outro trabalho, Hohle e Weissenborn (2000) conduziram um experimento com crianças alemãs de 8.15 e 12.5 meses de idade, através da técnica de escuta preferencial. Os bebês foram divididos em dois grupos. O primeiro, formado por crianças de 8;15 a 10;15 e o segundo de $10 ; 15$ a 12.15 .

Em cada grupo, uma subdivisão foi feita, de forma que, durante a familiarização, metade das crianças ouviu DPs (der Kahn, "o barco"; das Tor, "o portão") e as outras escutaram somente a nomes bissilábicos (vulkan; pastor), que apresentavam a segunda sílaba fonologicamente semelhante aos nomes monossílabos utilizados nos DPs (Kan e 
Tor). Desse modo, seria possível analisar se as crianças segmentariam o DP, reconhecendo os nomes monossílabos na fase de teste, quando combinados a outros determinantes.

$\mathrm{Na}$ fase de teste, todos os bebês foram expostos às mesmas passagens, que eram constituídas por DPs formados pelos nomes familiarizados (Kahn e Tor), porém com determinantes diferentes, e DPs com nomes não familiarizados.

A previsão é de que, se a criança já é sensível aos determinantes da língua, sendo capaz de segmentar o DP em Determinante e Nome, o grupo familiarizado com os DPs escutaria por mais tempo as passagens com Kahn e Tor, já que reconheceriam esses nomes. Por outro lado, as crianças que foram familiarizadas apenas com nomes não se mostrariam interessadas nas passagens, pois não encontrariam os nomes familiarizados e não reconheceriam os monossílabos Kahn e Tor.

A análise dos resultados revelou que não houve uma diferença significativa no tempo de escuta para as crianças menores. Já para os bebês mais velhos, a diferença encontrada foi marginalmente significativa para o grupo familiarizado com os DPs ( $\mathrm{p}=.061$ ), que apresentou uma média de escuta de $7349 \mathrm{msec}$ para as passagens que continham os itens familiarizados e de $6381 \mathrm{msec}$ para as que não tinham os nomes familiarizados. Já para o grupo familiarizado com nomes, não houve diferença significativa.

Partindo dos resultados não conclusivos obtidos em pesquisa realizada com bebês de 8 meses, conforme apresentado previamente, Shi e colaboradores (2006) investigaram se crianças canadenses de origem francesa de 6 meses de idade seriam capazes de segmentar os itens funcionais, em particular, os artigos definidos e indefinidos, do fluxo da fala e se a frequência seria um fator determinante neste processo. Além disso, um segundo objetivo do trabalho foi investigar a natureza da codificação fonética dos itens funcionais.

A investigação com crianças mais novas justificou-se pelo fato de, em francês, os itens funcionais apresentarem uma distribuição mais regular e serem menos reduzidos foneticamente do que no inglês, o que os tornaria mais salientes para as crianças. Não é claro, contudo, se a saliência considerada pelos autores é do tipo acústica ou perceptual. Dessa forma, assumiu-se a hipótese de que, aos 6 meses, crianças adquirindo o francês seriam capazes de reconhecer os artigos da língua.

No primeiro experimento, as crianças foram divididas em dois grupos. No primeiro, ouviram, durante a fase de familiarização, o artigo definido la, apresentado de forma isolada, enquanto o segundo grupo foi exposto ao indefinido des. Já na fase de teste, ambos os grupos escutaram a dois tipos de ensaios, apresentados de forma alternada: La+sangle e des+ sangles.

Através da técnica de olhar preferencial, mediram-se os tempos de olhar para os ensaios contendo o item familiarizado e os ensaios com o item não familiarizado. A análise dos resultados demonstrou um tempo de olhar maior para as sequências com itens familiarizados (aproximadamente $58 \mathrm{sec)}$ em relação aos não-familiarizados (aproximadamente $53 \mathrm{sec})$. A diferença mostrou-se significativa $(\mathrm{p}=.02)$, sugerindo, segundo as autoras, que aos 6 meses, as crianças começam a segmentar os artigos de sua língua. 
Tais resultados convergem, pois, para a hipótese assumida e sugerem que aos 6 meses de idade as crianças são sensíveis aos determinantes da língua, pelo menos os mais frequentes, reconhecendo-os como unidades independentes.

Vale lembrar que, no experimento conduzido em inglês, com bebês de 8 meses, os resultados alcançados por Shi e colaboradores (2003) não foram significativos estatisticamente, sugerindo que a sensibilidade aos itens funcionais ocorreria mais tardiamente. Embora divergentes, os resultados encontrados por Hohle e Weissenborn não invalidam o trabalho conduzido por Shi, visto que, como os próprios pesquisadores afirmam, os resultados não podem ser generalizados para outras línguas, já que cada uma apresenta sua especificidade. Em inglês, por exemplo, os itens funcionais apresentam mais reduções vocálicas do que em alemão, o que poderia dificultar o seu reconhecimento por crianças.

O conjunto de trabalhos aqui apresentados aponta para a relevância dos determinantes para a aquisição da linguagem. Tais itens, juntamente com pistas prosódicas, auxiliam as crianças na tarefa de segmentação do fluxo da fala e na categorização de palavras, servindo, portanto, de pistas fundamentais à inserção na sintaxe da língua e à aquisição lexical.

\section{1) A sensibilidade de bebês aos determinantes do português do Brasil}

Embora existam poucos trabalhos em Português do Brasil voltados à investigação da capacidade perceptual dos bebês aos itens funcionais da língua, destacamos os de Teixeira (2013) e Uchôa (2013), que vão ao encontro dos resultados apresentados em línguas, na medida em que apontam para a importância desses itens e, particularmente, dos determinantes, no início do processo de aquisição do português brasileiro por bebes com idade média de 13 meses.

Ambos os trabalhos utilizaram a técnica de escuta preferencial. Em Uchôa (2013), investigou-se a sensibilidade de bebês aos determinantes da língua e sua capacidade de segmentação do sintagma determinante em unidades menores. Este trabalho foi uma continuação da pesquisa realizada por Name (2002), que também investigou a sensibilidade de crianças de 17 meses aos itens funcionais utilizando pequenas histórias em duas versões: uma modificada (com pseudoitens) e uma não modificada (com itens funcionais reais).

O trabalho de Uchôa amplia e se diferencia do anterior por ter utilizado uma técnica experimental diferente, restringido a análise aos determinantes, que estavam inseridos em contextos sintáticos menores (sintagmas) e investigado crianças mais novas. Para isso, dividiu-se as 16 crianças em dois grupos, de modo que todas elas participarem das duas condições gramaticais, quais sejam: condição gramatical, formada por determinantes (o/um/este/aquele) da língua seguidos por pseudopalavras (bape/tofe) +adjetivo (lindo) e agramatical, em que pseudodeterminantes (ône/ór/ugi/ófupi) eram combinados a pseudopalavras +adjetivo.

Após serem familiarizadas às pseudopalavras, as crianças procediam à fase de teste, em que escutavam aos estímulos e o tempo de fixação do olhar na tela era medido. Os resultados indicaram uma preferência pelos determinantes reais da língua (9.18 
segundos) em detrimento dos pseudodeterminantes ( 7.88 segundos), com uma diferença estatisticamente significativa entre as duas condições para os dois grupos de participantes $(\mathrm{p}=.0008)$. Dessa forma, os resultados sugerem que a identificação dos pseudonomes foi facilitada pela presença dos determinantes da língua que já lhe são, desde tenra idade, reconhecidos. Além disso, esses resultados evidenciam a capacidade de a criança segmentar o sintagma determinante, na medida em que ela foi capaz de diferenciar o determinante/pseudodeterminante da pseudopalavra, segmentando o sintagma em D+N.

Em outro trabalho, Teixeira (2013) investigou a capacidade de crianças utilizarem itens funcionais (determinantes e pronomes pessoais do caso reto) para categorizarem uma nova palavra como nome ou verbo.

As crianças que participaram da pesquisa foram divididas em dois grupos, um deles na condição determinante (a, uma, essa) e outro na condição pronome (ele, ela, você). A esses itens foram combinados dois pseudonomes, piva e dema.

Durante a familiarização, as crianças do grupo 1 ouviram a sequências formadas por a/uma+piva; a/uma+dema, enquanto o grupo 2 ouviu ele/ela piva; ele/ela+dema.

$\mathrm{Na}$ fase de teste, ambos os grupos foram apresentados a um novo determinante (essa) + pseudopalavra e a um novo pronome (você) +pseudopalavra. Assim, para o grupo 1, a condição pronome é agramatical, da mesma forma que para o grupo 2, a condição determinante é agramatical.

Para ambos os grupos, o tempo de fixação foi maior para a condição congruente à familiarização e a diferença para as duas condições mostrou-se significativa $(p=.015)$. Os resultados sugerem que os bebês generalizaram os determinantes a uma mesma categoria e os pronomes a uma outra categoria diferente. Portanto, evidencia-se que as crianças utilizam os determinantes e os pronomes pessoais como pistas para reconhecimento da categoria gramatical da palavra seguinte como nome, no caso de vir precedido por um determinante, ou verbo, quando posposto a um pronome pessoal.

\section{Considerações finais}

Este trabalho buscou lançar luz sobre o intrigante fenômeno da aquisição da linguagem, buscando desvelar os mecanismos envolvidos nesse processo, de modo a entender o que de fato a criança deve adquirir da sua língua e de que modo a criança passa de um estágio inicial para um estágio final de aquisição linguística. Nesse ínterim, viabilizamos uma proposta teórica que concilia um modelo formal de língua - $\mathrm{o}$ Programa Minimalista - com um modelo psicolinguístico - bootstrapping fonológico. Dessa forma, demonstramos que as informações relevantes e específicas de uma língua encontram-se nos trações formais presentes nos itens formais e que, portanto, são esses traços que devem ser adquiridos pela criança no início de aquisição de sua língua materna. O reconhecimento desses traços ocorre por meio do sistema perceptual da criança que atua de modo a captar, no fluxo contínuo da fala a que a criança está exposta, as informações salientes dos itens funcionais, suas características fonéticas, prosódicas e distribucionais. São essas informações que irão desencadear o processo e alçar a criança à gramática de sua língua. 
Uma série de trabalhos experimentais, conduzidos em diversas línguas apresentam indícios do papel fundamental exercido pelos itens funcionais, sugerindo que já desde muito novas, por volta dos 10.5 meses de idade, as crianças são sensíveis às propriedades desses itens, reconhecendo-os em sua língua, diferenciando-os dos itens lexicais e utilizando-os para diferenciar categorias gramaticais e segmentar o sintagma.

O conjunto de trabalhos relatados e a proposta teórica defendida parecem dar conta de explicar de que modo a criança adquire a sua língua. Mais do que isso, sugerem que o papel facilitatório dos itens funcionais não se restringe a uma ou algumas línguas específicas, mas, ao contrário, atua nas mais diferentes línguas, já que são portadores das informações gramaticais de uma língua.Assim, apesar de sua ocorrência tardia na produção, já são reconhecidos na compreensão desde muito cedo.

\section{Referências}

\section{CHOMSKY, N. The Minimalist Program. Cambridge, MA: MIT Press, 1995.}

CHRISTOPHE, A.; GUASTI, T.; NESPOR, M.; DUPOUX, E.; VAN OOYEN, B. Reflections on phonological bootstrapping: its role for lexical and syntactic acquisition. Language and Cognitive Processes, v. 12, n. 5/6, p. 585-612, 1997.

HOHLE,B. \&WEISSENBORN,J. (2003).German-learning infant's ability to detect unstressed closed-class elements in continuous speech. Developmental Science, 6:2, 122-127.

NAME, M.C. Habilidades perceptuais e linguísticas no processo de aquisição do sistema de gênero no português. Tese (Doutorado) PUC RJ, 2002.

NAME, M. C.; Corrêa, L.M.S. Explorando a escuta, o olhar e o processamento sintático: metodologia experimental para o estudo da aquisição da língua materna em fase inicial. In: Letícia M. S. Corrêa. (Org.). Estudos sobre Aquisição da Linguagem e Desvios no Desenvolvimento Lingüístico. 1ed.Rio de Janeiro / São Paulo: Editora da PUC-Rio / Loyola, 2006, v. , p. 79-100.

Corrêa,L.M.S. A aquisição da linguagem no arcabouço minimalista sob uma perspectiva psicolingüística. In: FERRARI-NETO, J; SILVA, C. R. T. (org.) Programa Minimalista em foco: princípios e debates. Curitiba, PR: Editora CRV, p. 271300,2012 .

SHADY, M. Infants' sensitivity to function morphemes. PhD Dissertation at Univ. Buffalo, 1996.

SHAFER, V.; SHUCARD, D.; SHUCARD, J.; GERKEN, LA. An Electrophysiological Study of Infants' Sensitivity to the Sound Patterns of English Speech. Journal of Speech, Language and Hearing Research, v. 41, p. 87 -886, 1998.

SHI, R.; WERKER, J. \& CUTLER, A. (2003). Function words in early speech perception. $15^{\text {th }} \mathrm{ICPhS}$ Barcelona, p. 3009-3012. 
TEIXEIRA, S. A. A Identificação das Categorias Lexicais V(erbo) e $\mathbf{N}(0 \mathrm{ome})$ a partir de uma Categoria Funcional. Dissertação (Mestrado em Linguística) Universidade Federal de Juiz de Fora, 2013.

UCHÔA, D. N. A sensibilidade à forma fônica e à frequência na identificação de Determinantes por crianças brasileiras. Dissertação (Mestrado). Universidade Federal de Juiz de Fora, 2013. 